\title{
Phenylephrine to increase blood flow in the radial artery used as a coronary bypass conduit
}

\author{
Nikolaos Skubas, MD, ${ }^{a}$ Hendrick B. Barner, MD, ${ }^{\mathrm{b}}$ loanna Apostolidou, MD, and Demetrios G. Lappas, MDa
}

From the Divisions of Cardiothoracic Anesthesiology ${ }^{\mathrm{a}}$ and Cardiothoracic Surgery, ${ }^{\mathrm{b}}$ Washington University School of Medicine, St Louis, Mo.

Supported in part by a grant from the Division of Cardiothoracic Surgery, Department of Surgery, Washington University School of Medicine, St Louis, Mo.

Received for publication Oct 19, 2004; revisions received Jan 26, 2005; accepted for publication Feb 6, 2005.

Address for reprints: Hendrick B. Barner, MD, 6125 Clayton Ave, Suite 430, St Louis, MO 63139 (E-mail: hendrick.barner@ tenethealth.com).

J Thorac Cardiovasc Surg 2005;130:687-92

$0022-5223 / \$ 30.00$

Copyright $\odot 2005$ by The American Association for Thoracic Surgery

doi:10.1016/j.jtcvs.2005.02.066
Objective: The radial artery has more smooth muscle in its wall than the other arterial conduits and is known to be vasospastic. Because it is frequently necessary to use vasoconstrictors early after coronary bypass surgery we investigated the effects of phenylephrine on conduit flow in this setting.

Methods: Thirty patients undergoing coronary artery bypass with all arterial conduits in which the radial artery was used as a T-graft were randomly assigned to receive intravenous infusions of normal saline $(\mathrm{n}=10)$; nitroglycerin, $0.5 \mu \mathrm{g} \cdot \mathrm{kg}$ $\cdot \min (\mathrm{n}=11)$; or nicardipine, $0.5 \mu \mathrm{g} \cdot \mathrm{kg} \cdot \min (\mathrm{n}=9)$, beginning early in the operation. After discontinuation of cardiopulmonary bypass and achievement of stable hemodynamics, control measurements were obtained, and this was followed by phenylephrine infusion to achieve a $20 \%$ increase in mean arterial pressure, after which the measurements were repeated.

Results: Mean radial artery flow increased similarly in all groups: normal saline, $40 \% \pm 25 \%$; nicardipine, $37 \% \pm 27 \%$; nitroglycerin, $48 \% \pm 36 \%(P=.533)$. Comparable changes occurred in arterial pressure and systemic vascular resistance, whereas the cardiac index remained unchanged.

Conclusion: Radial artery blood flow increases when the mean arterial pressure is increased with phenylephrine. There was no evidence of a conduit vasoconstrictive effect, which could limit or reduce conduit flow. Vasocontriction with phenylephrine is appropriate to provide adequate perfusion pressure for radial artery grafts.

$\mathrm{T}$ The radial artery has had increasing use over the past decade. It has a vasospastic tendency noted at harvest, and it has been recommended that its use be accompanied by infusion of diltiazem. ${ }^{1,2}$ In vitro studies demonstrate that the radial artery contracts more strongly than the internal thoracic artery when exposed to norepinephrine, serotonin, thromboxane A2 mimetic, ${ }^{3}$ or endothelin. ${ }^{4}$ Nitroglycerin (TNG) is a more effective radial artery dilator than is diltiazem. ${ }^{5,6}$

It is frequently necessary to use vasoconstricting agents immediately after cardiopulmonary bypass to provide adequate perfusion pressure. Phenylephrine (PHE), a synthetic sympathomimetic agent chemically related to epinephrine and ephedrine, is often used for this purpose.

We evaluated the effect of PHE on the flow of the radial artery when used as a coronary artery bypass conduit in the presence or absence of a vasodilator drug.

\section{Patients and Methods}

The study was approved by our institution's human studies committee, and all patients provided written informed consent. Thirty adult patients who underwent primary elective coronary artery bypass grafting with the left internal thoracic artery and the radial artery as a T-graft ${ }^{7}$ were studied prospectively. Exclusion criteria included renal, hepatic, or respiratory insufficiency; preoperative circulatory support with intra-aortic balloon counterpulsation; inotropic or vasoactive drug infusion; or allergy to nicardipine (NIC), TNG, or PHE. No patient was excluded on the basis of preoperative indices of heart function. 
All patients received their prescribed medications up until the morning of the operation. Morphine, lorazepam, and scopolamine in individualized doses were administered as premedication. All patients received a standardized general endotracheal anesthetic regimen based on opioids (fentanyl, 0.15-0.20 $\mu \mathrm{g} / \mathrm{kg}$ ) and supplemented with midazolam, 5 to $10 \mathrm{mg}$, and pancuronium. Inhaled isoflurane was administered at a maximum of $0.4 \%$ end-tidal concentration.

The patients were randomly allocated to 3 groups on the basis of a computer-generated table of random numbers. After baseline hemodynamic data had been obtained and before sternal split, one of the following infusions was started: NIC, 0.5-0.7 $\mu \mathrm{g} \cdot \mathrm{kg} \cdot \mathrm{min}$; $\mathrm{TNG}, 0.5-0.7 \mu \mathrm{g} \cdot \mathrm{kg} \cdot \mathrm{min}$; or normal saline $0.9 \%$ (NS).

During cardiopulmonary bypass, systemic flows were kept at greater than $2.4 \mathrm{~L} \cdot \min ^{-1} \cdot \mathrm{m}^{-2}$, and mean arterial pressure (MAP) was maintained between 40 and $80 \mathrm{~mm} \mathrm{Hg}$, with pump flow adjustment and bolus doses of PHE or TNG. Blood gas analysis was performed every 30 minutes. During bypass, the patients' body temperature was kept at $33^{\circ} \mathrm{C}$, and blood cardioplegia was administered at the same temperature.

At rewarming, after release of the aortic crossclamp, the isoflurane blended into the bypass circuit was switched off, so that at the time of weaning from bypass, the isoflurane end-tidal concentration was less than $0.1 \%$. Inotropic support was instituted in those patients with poor preoperative systolic function, diastolic function, or both.

The radial artery was harvested without skeletonization. After conduit harvest, heparin (300 U/kg body weight) was administered, and the radial artery was anastomosed to the proximal left internal thoracic artery (T-graft). Both conduits were filled with heparinized blood containing papaverine $(2 \mathrm{mg} / \mathrm{mL})$ and were exposed to arterial pressure for 10 minutes during cannulation for cardiopulmonary bypass. No other graft interventions were attempted. This achieved relaxation of harvest spasm, as confirmed by means of inspection of conduits and assessment of free flow. During cardiopulmonary bypass, the left internal thoracic artery was anastomosed to the left anterior descending coronary artery and its branches, and the radial artery was anastomosed to the right coronary artery and/or the circumflex arteries and their branches.

After separation from cardiopulmonary bypass and achievement of hemodynamic stability, the heart was paced with epicardial atrial leads at 90 beats/min, and the experimental protocol was carried out. The surgeon measured the blood flow through the radial artery graft (QRA) by using a calibrated transonic flowmeter (Transonic Systems Inc, Ithaca, NY) while the anesthesiologist collected the hemodynamic data (control or pre-PHE measurements). The transonic flowmeter consists of an open ring that is placed around the grafted radial artery without skeletonization, distal to the $\mathrm{T}$ anastomosis, and proximal to the first distal anastomosis. Then MAP was increased by $20 \%$ with infusion of PHE. After the target MAP was obtained, the above measurements were repeated (after PHE). To eliminate physician bias and at the same time to ensure appropriate and ethical clinical care to all patients, the surgeon was blinded to the patient's group, as well as the hemodynamic measurements, and the anesthesiologist was blinded to the QRA measurements.

The following variables were measured: QRA, MAP, mean pulmonary artery pressure, central venous pressure, pulmonary capillary wedge pressure, cardiac output in triplicate at end-expiration, and heart rate. Stroke volume (SV), cardiac index, systemic vascular resistance (SVR), and pulmonary vascular resistance were calculated by known formulas.

Statistical analysis was performed on Stata 4.0 software (Stata Corp, College Station, Tex). Categorical (binary) data were compared by the $\chi 2$ test. Continuous data between groups were compared by analysis of variance with the Bonferroni correction where necessary. Continuous variables within the same group were compared by the Student $t$ test, assuming where appropriate that the variance was unequal.

\section{Results}

The demographic data, preoperative medications, and cardiovascular data (history of previous myocardial infarction and incidence of comorbid diseases, such as diabetes, previous cerebrovascular events, or smoking) did not differ among groups (Table 1).

Native coronary artery disease (percentage of obstruction), as well as the presence or absence of collateral circulation, were similar, both clinically and statistically, among the participating patients (Table 2). The left anterior descending artery was grafted with the left internal thoracic artery, and the circumflex and right coronary arteries were grafted with the radial artery. The number of distal anastomoses constructed was not statistically different among the 3 groups. At least 2 distal anastomoses were constructed with the radial artery in all patients. Inotropic support with dobutamine, amrinone, or both, was required in a small number of patients (NIC, 2; NS, 2; TNG, 4; $P=.868$ ).

Before PHE administration, the MAP was similar among the groups, the SVR was lower in the NIC group and higher in the NS group, and the cardiac output was higher in the NIC group, whereas the QRA was higher in the TNG group and lower in the NS group (Table 3). In all groups PHE administration resulted in a clinically and statistically significant increase of MAP, SVR, and QRA (Figure 1) in the presence of unchanged SV (and cardiac index) and right and left heart filling pressures (Table 3). After PHE, MAP was clinically similar in all groups, SVR continued to be lower in the NIC group and higher in the NS group, and QRA was greater in the TNG group and lower in the NS group. The SV did not change after PHE, remaining higher in the NIC group.

The radial artery flow tracing had a biphasic wave form composed of a systolic and a diastolic wave in all patients. The diastolic wave was greater than the systolic wave in both pre-PHE and post-PHE periods (Figure 2).

\section{Discussion}

The principal finding of this study is that PHE increased the blood flow of the T-grafted radial artery. This increase occurred in all patients irrespective of the presence or absence of the concurrent infusion of a vasodilator (TNG or NIC). 
TABLE 1. Demographic data and preoperative medications

\begin{tabular}{|c|c|c|c|c|}
\hline & NIC $(n=9)$ & NS $(n=10)$ & TNG $(n=11)$ & $P$ value \\
\hline Age $(y)^{*}$ & $54 \pm 8$ & $60 \pm 8$ & $58 \pm 10$ & .46 \\
\hline $\operatorname{Sex}(F / M)$ & $2 / 7$ & $4 / 6$ & $2 / 9$ & .59 \\
\hline Height $(\mathrm{cm})^{*}$ & $177 \pm 11$ & $171 \pm 10$ & $166 \pm 27$ & .39 \\
\hline Weight $(\mathrm{kg})^{*}$ & $99 \pm 16$ & $85 \pm 18$ & $97 \pm 29$ & .35 \\
\hline $\mathrm{BSA}(\mathrm{m} 2)^{*}$ & $2.2 \pm 0.3$ & $1.9 \pm 0.2$ & $2.0 \pm 0.2$ & .19 \\
\hline$\beta$-blockers & 7 & 5 & 5 & .34 \\
\hline $\mathrm{Ca}++$ blockers & 1 & 1 & 4 & .31 \\
\hline ACE inhibitors & 3 & 2 & 3 & .88 \\
\hline Heparin & 1 & 3 & 1 & .47 \\
\hline Nitrates & 3 & 2 & 3 & .88 \\
\hline Aspirin & 8 & 8 & 9 & 1.0 \\
\hline Hypertension & 3 & 4 & 8 & .22 \\
\hline Shortness of breath & 2 & 4 & 4 & .71 \\
\hline Congestive heart failure & 0 & 3 & 0 & .06 \\
\hline Angina & 6 & 8 & 10 & .77 \\
\hline Diabetes mellitus & 3 & 2 & 2 & .76 \\
\hline Cerebrovascular disease & 2 & 0 & 2 & .42 \\
\hline Smoking & 1 & 2 & 5 & .23 \\
\hline Myocardial infarction & 5 & 4 & 3 & .39 \\
\hline LVEDP $(\mathrm{mm} \mathrm{Hg})^{*}$ & $18 \pm 5$ & $15 \pm 5$ & $14 \pm 5$ & .38 \\
\hline $\mathrm{EF}(\%)^{*}$ & $45 \pm 10$ & $52 \pm 8$ & $47 \pm 15$ & .39 \\
\hline LV score* & $8.3 \pm 2.6$ & $6.3 \pm 1.6$ & $6.6 \pm 2.3$ & .12 \\
\hline
\end{tabular}

$N I C$, Nicardipine; $N S$, normal saline; TNG, nitroglycerin; $B S A$, body surface area; $A C E$, angiotensin-converting enzyme; $L V E D P$, left ventricular end-diastolic pressure (data for 17 patients: 6 in the nicardipine group, 6 in the normal saline group, and 5 in the nitroglycerin group); $E F$, ejection fraction (data for 23 patients: 7 in the nicardipine group, 8 in the normal saline group, and 8 in the nitroglycerin group); LV score, left ventricular score. *Mean \pm SD.

Graft flow is similar in venous and arterial coronary bypass grafts when there is occlusion or severe coronary stenosis and is primarily related to the size of the outflow bed (amount of viable myocardium). Arterial conduit flow will be less if there is competitive coronary flow usually caused by a less severe coronary stenosis or occasionally abundant collateral flow because of the similarity in diameter of the coronary and conduit arteries and the greater

TABLE 2. Angiographic data and bypass grafts

\begin{tabular}{|c|c|c|c|c|}
\hline & NIC $(n=9)$ & NS $(\mathbf{n}=10)$ & $\operatorname{TNG}(\mathbf{n}=11)$ & $P$ value \\
\hline \multicolumn{5}{|l|}{ LAD disease } \\
\hline Obstruction $(\%)^{*}$ & $82 \pm 15$ & $77 \pm 28$ & $70 \pm 24$ & .55 \\
\hline No. of distal anastomoses & 11 & 13 & 19 & .44 \\
\hline No. of grafts: ITA/RA & $9 / 2$ & $10 / 3$ & $16 / 3$ & $.27 / .95$ \\
\hline \multicolumn{5}{|l|}{ Circumflex disease } \\
\hline Obstruction $(\%)^{*}$ & $73 \pm 29$ & $79 \pm 17$ & $74 \pm 29$ & .86 \\
\hline No. of distal anastomoses: RA & 10 & 14 & 15 & .68 \\
\hline \multicolumn{5}{|l|}{ Right coronary disease } \\
\hline Obstruction $(\%)^{*}$ & $88 \pm 17$ & $81 \pm 29$ & $72 \pm 19$ & .40 \\
\hline No. of distal anastomoses: RA & 8 & 9 & 9 & .95 \\
\hline \multicolumn{5}{|l|}{ Distal anastomosis } \\
\hline Total & 29 & 36 & 43 & .41 \\
\hline No. of LITA/RA & $9 / 20$ & $10 / 26$ & $16 / 27$ & $.27 / .41$ \\
\hline \multicolumn{5}{|l|}{ Collateral circulation } \\
\hline Absent $/ \mathrm{R} \rightarrow \mathrm{L} / \mathrm{R} \leftarrow \mathrm{L}$ & $5 / 2 / 2$ & $7 / 1 / 2$ & 10/0/1 & .40 \\
\hline CBP duration $(\min )^{*}$ & $127 \pm 33$ & $142 \pm 49$ & $140 \pm 26$ & .63 \\
\hline AXC duration (min)* & $108 \pm 32$ & $111 \pm 15$ & $121 \pm 27$ & .51 \\
\hline
\end{tabular}

NIC, Nicardipine; NS, normal saline; TNG, nitroglycerin; $L A D$, left anterior descending coronary artery; ITA, internal thoracic artery; $R A$, radial artery; $L I T A$, left internal thoracic artery; $R \rightarrow L$, right to left; $R \leftarrow L$, left to right; $C B P$, cardiopulmonary bypass; $A X C$, aortic crossclamp. *Mean $\pm \mathrm{SD}$. 
TABLE 3. Hemodynamics

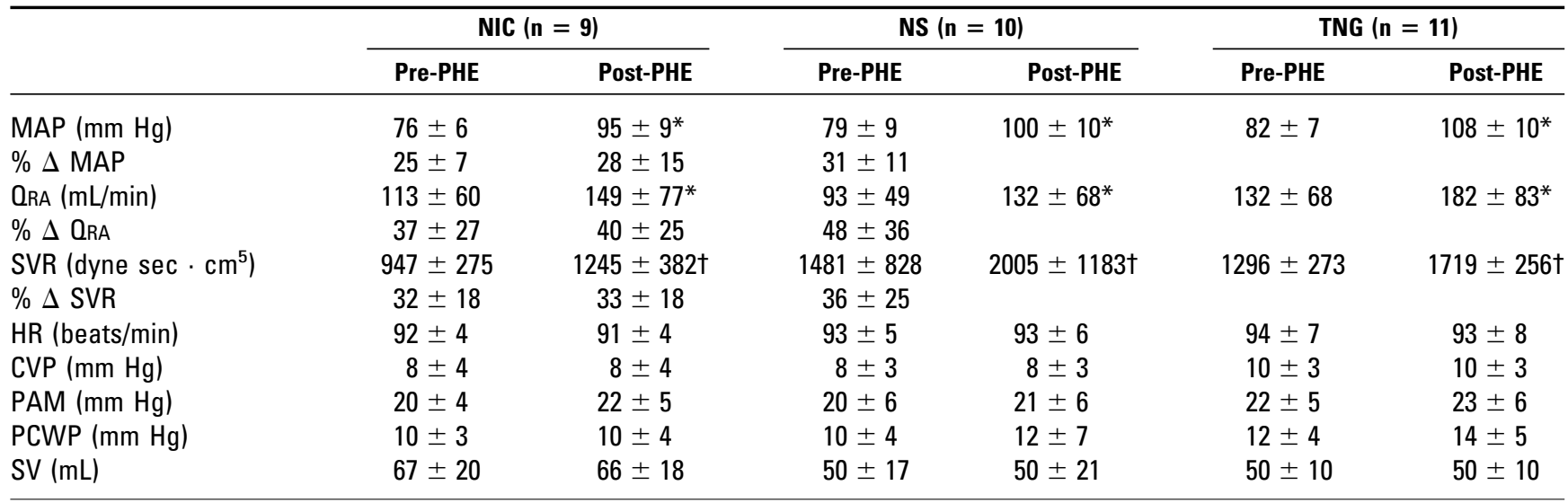

All data are presented as means \pm SD. NIC, Nicardipine; $N S$, normal saline; TNG, nitroglycerin; $P H E$, phenylephrine; MAP, mean arterial pressure; $Q_{R A}$ radial artery graft flow; SVR, systemic vascular resistance; $H R$, heart rate; $C V P$, central venous pressure; $P A M$, mean pulmonary artery pressure; $P C W P$, pulmonary capillary wedge pressure; $S V$, stroke volume. $* P<.001$ versus pre-PHE. $\dagger P<.003$ versus pre-PHE.

length of the conduit with correspondingly greater resistance to flow. This phenomenon does not usually prevail with vein grafts because of their much greater diameter and therefore flow capacity because the primary resistance to flow is the cross-sectional area of lumen according to the Poiseuille equation.

Baseline (pre-PHE) radial artery flow was similar in the saline-treated patients to that measured in 200 patients $(88$
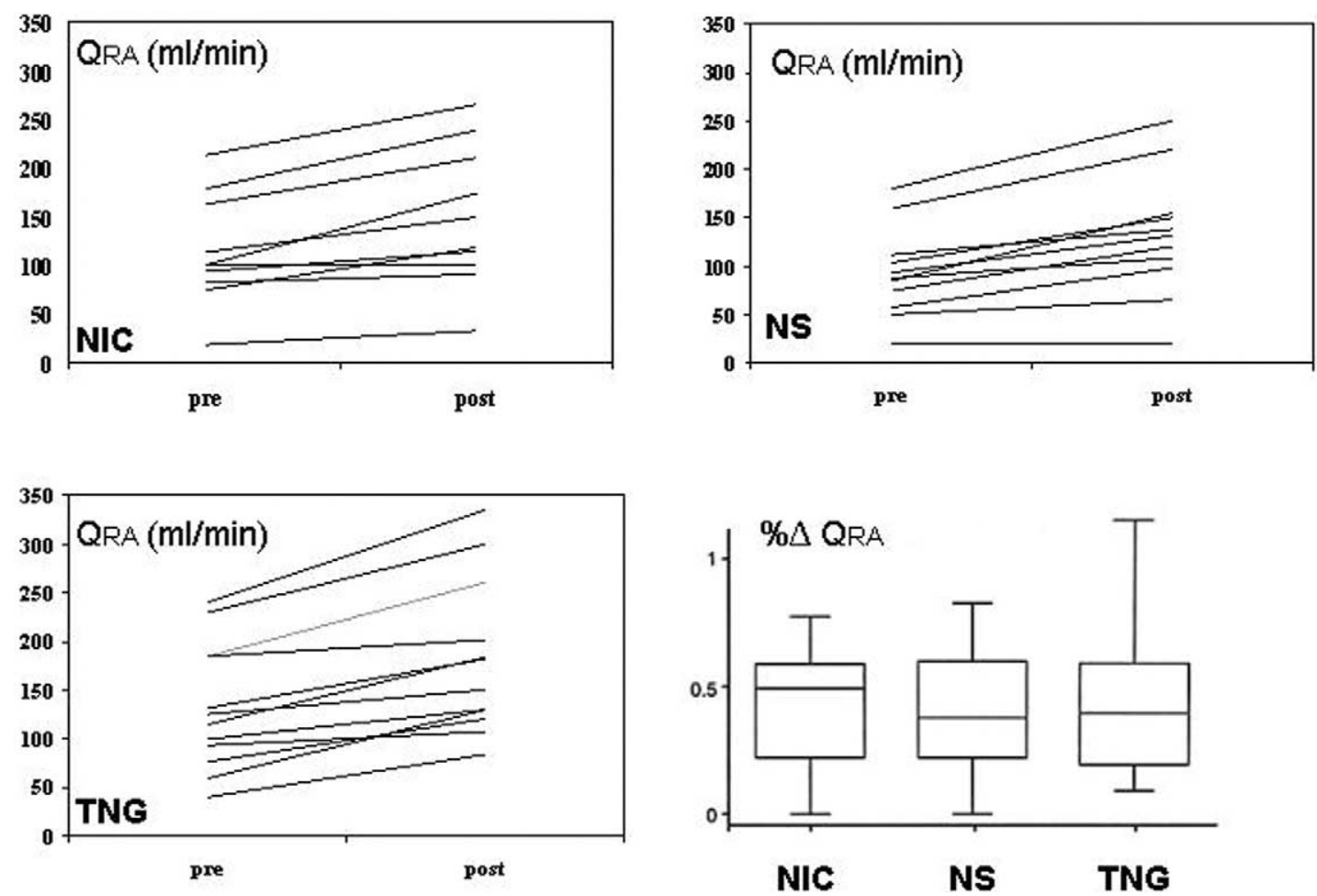

Figure 1. Radial artery flow at control (pre) and after increasing mean arterial pressure $20 \%$ (post) is depicted for each patient in the 3 groups: nicardipine (NIC), normal saline (NS), and nitroglycerin (TNG). Lower right panel summarizes the percentage increase in flow for each group, which was significant within each group $(P<.001)$ but not between groups. $Q_{R A}$, Radial artery flow; $P H E$, phenylephrine; $\% \Delta Q_{R A}$, percentage change in radial artery flow. 


\section{Pre PHE}
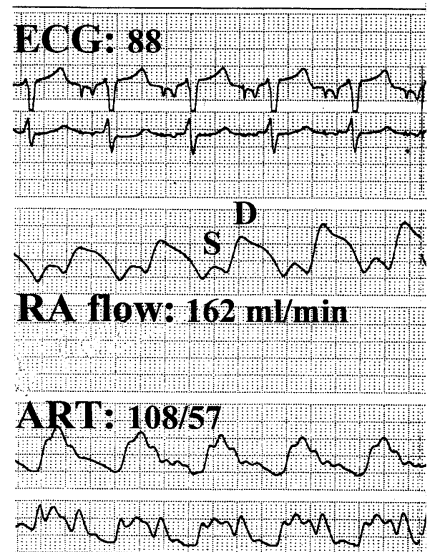

PA: 23/12, w: 8

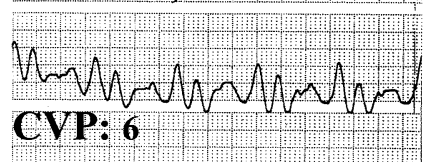

\section{Post PHE}

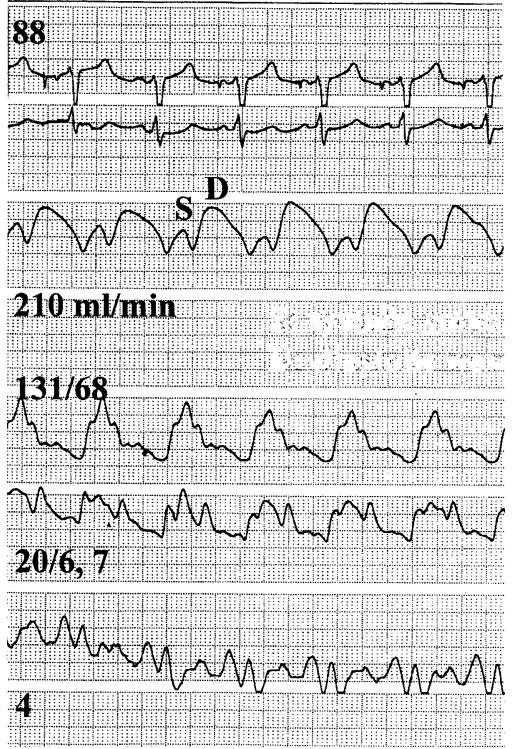

Figure 2. These are typical tracings from a patient receiving nicardipine before (pre) and after (post) infusion of phenylephrine (PHE). From top to bottom are electrocardiogram (ECG), transonic radial artery (RA) flow ( $S$, systolic wave; $D$, diastolic wave), arterial pressure $(A R T)$, pulmonary artery pressure $(P A)$, wedge $(W)$ pressure, and central venous pressure (CVP). Similar tracings were recorded from all patients.

$\pm 49 \mathrm{~mL} / \mathrm{min}$; MAP, $80 \pm 10 \mathrm{~mm} \mathrm{Hg}) .{ }^{8}$ Graft flow was greater in the patients receiving NIC or TNG both before PHE and after PHE, but this did not achieve significance compared with the NS-treated patients. These agents could have dilated the conduit and the coronary vessels. However, the primary determinant of conduit flow, assuming there is no significant competitive flow, is the resistance of the coronary vascular bed, unless there is conduit spasm. A decrease in conduit diameter to less than its usual or optimal diameter could reduce conduit flow, and this has been a concern over the use of vasoconstrictors in the postbypass interval and was the primary reason for this study. Because we did not measure conduit diameter, we cannot exclude a PHE effect. Likewise, we cannot conclude that conduit diameter did not increase because of flow-mediated vasodilatation as MAP and conduit flow increased (after PHE). In another series from our center, we have found that radial artery free flow in the T-graft configuration was $161 \pm 81$ $\mathrm{mL} / \mathrm{min}(\mathrm{n}=200)$ at a MAP of $78 \pm 9 \mathrm{~mm} \mathrm{Hg},{ }^{8}$ which was less than the $182 \pm 83 \mathrm{~mL} / \mathrm{min}$ measured in the TNG group after PHE in the current study. This would suggest that TNG might have caused an increase in the grafted radial artery diameter, flow-mediated vasodilation took place, or both.

An additional concern is the anastomosis of the radial artery to the internal thoracic artery, suggesting that flow through the T-graft might be limited by the proximal segment of the internal thoracic artery. We have shown that the total T-graft free flow (both ends measured simultaneously) was $26 \% \pm 14 \%$ less than the sum of each component's free flow $(226 \pm 84 \mathrm{~mL} / \mathrm{min}$ vs $298 \pm 101 \mathrm{~mL} / \mathrm{min}$, both at a MAP of $79 \mathrm{~mm} \mathrm{Hg}){ }^{8}$ Although the T-graft configuration can potentially limit total flow, experience indicates that the internal thoracic artery is not vulnerable to clinical use of vasoconstricting agents. Thus, on the basis of its known propensity for vasoconstriction, the radial artery becomes the potential flow-limiting component of the T-graft. Our observations indicate that PHE does not elicit this potential; however, that might not necessarily apply to other vasoconstrictors.

The flow pattern in the radial artery was similar before and after PHE and consisted of a small systolic wave and a wider, higher diastolic wave (Figure 2). This pattern is typical of the flow wave in the coronary artery or bypass grafts on the left side of the heart, as opposed to those supplying the right ventricle, where the systolic wave is greater and the diastolic component is reduced. ${ }^{9}$ Restricted inflow results in flattening of the flow waves, and increased coronary vascular resistance prevents an increase in or could decrease radial artery flow, neither of which occurred after PHE.

We believe that our harvesting technique with clipping or ultrasonic coagulation of the radial artery branches and gentle traction on the radial artery results in minimal trauma to the conduit. In addition, the radial artery is maintained in 
room temperature blood for 5 to 20 minutes until the Tanastomosis is performed, followed by exposure of the conduits to arterial pressure in the presence of intraluminal papaverine. Atraumatic harvesting of the radial artery ensures excellent endothelial preservation and function, with basal production of nitric oxide, as well as flow-mediated shear stress-stimulated nitric oxide release.

The small number of subjects is one of the limitations of the study. The free QRA depends on perfusion pressure, lumen area, and endothelial function, whereas the QRA depends additionally on the technique used to measure it (eg, electromagnetic vs transonic flowmeters and calibration). Assuming a QRA of 100 to $110 \mathrm{~mL} / \mathrm{min}$ with a standard deviation of 50 to $60 \mathrm{~mL} / \mathrm{min}$, a sample size of 8 patients per group would have been adequate to show a $20 \%$ increase in QRA, excluding an $\alpha$ error of .05. The study was not designed to evaluate differences of QRA on the basis of the administration of a vasodilator. However, there was no statistical difference between the groups regarding the magnitude of QRA increase. We did not examine the reactivity of the radial artery to PHE either in the forearm (in situ) or as a conduit. The purpose of the study was to investigate the clinical effects of PHE on QRA, as measured with the flowmeter and demonstrated by the common clinical monitoring devices.

We have not found it necessary to use vasodilating drugs either in the perioperative interval or systemically afterward. Likewise, we have not avoided specific vasoconstrict- ing drugs in patients receiving all arterial coronary revascularization because we believe that adequate blood pressure is required to maintain arterial conduit flow.

\section{References}

1. Acar C, Jebara VA, Portoghese M, Beyssen B, Pagny JY, Grare P, et al. Revival of the radial artery for coronary artery bypass grafting. Ann Thorac Surg. 1992;54:652-60.

2. Calafiore AM, Di Giammarco G, Teodori G, D'Annunzio E, Vitolla G, Fino C, et al. Radial artery and inferior epigastric artery in composite grafts: improved midterm angiographic results. Ann Thorac Surg. 1995; 60:517-24

3. Chardigny C, Jebara VA, Acar C, Descombes JJ, Verbeuren TJ, Carpentier A, et al. Vasoreactivity of the radial artery. Comparison with the internal mammary and gastroepiploic arteries with implications for coronary artery surgery. Circulation. 1993;88(5 Pt 2):II115-27.

4. He GW, Yang CQ. Characteristics of adrenoceptors in the human radial artery: clinical implications. J Thorac Cardiovasc Surg. 1998;115: 1136-41.

5. Cable DG, Caccitolo JA, Pearson PJ, O'Brien T, Mullany CJ, Daly RC, et al. New approaches to prevention and treatment of radial artery graft vasospasm. Circulation. 1998;98(Suppl II)II15-22.

6. Shapira OM, Xu A, Vita JA, Aldea GS, Shah N, Shemin RJ, et al. Nitroglycerin is superior to diltiazem as a coronary bypass conduit vasodilator. J Thorac Cardiovasc Surg. 1999;117:906-11.

7. Barner HB, Sundt TM, Bailey M, Zang Y. Midterm results of complete arterial revascularization in more than 1,000 patients using an internal thoracic artery/radial artery T-graft. Ann Surg. 2001;234:447-53.

8. Affleck DG, Barner HB, Bailey MS, Perry L, Maniar H, Prasad SM, et al. Flow dynamics of the internal thoracic and radial artery T-graft. Ann Thorac Surg. 2004;78:290-4.

9. Bach RG, Kern MJ, Donohue TJ, Aguirre FV, Caracciolo EA. Comparison of phasic blood flow velocity characteristics of arterial and venous coronary artery bypass conduits. Circulation. 1993;88(5 Pt 2):II133-40

\section{Online-www.aats.org}

Now you can get The Journal of Thoracic and Cardiovascular Surgery online. The Journal online brings you faster delivery time, easy searching of current and back issues, links to PubMed, AATS, WTSA, and other important sites, and more. Visit the Journal online today.

\section{Receive tables of contents by e-mail}

To receive the tables of contents by e-mail, sign up through our Web site at http://www.mosby.com/jtcvs

Choose E-mail Notification

Simply type your e-mail address in the box and click the Subscribe button.

Alternatively, you may send an e-mail message to majordomo@mosby.com.

Leave the subject line blank and type the following as the body of your message: subscribe jtcvs_toc

You will receive an e-mail to confirm that you have been added to the mailing list.

Note that TOC e-mails will be sent out when a new issue is posted to the Web site. 